\title{
Significance of pigment granules in the vitreous
}

\author{
A. M. HAMILTON AND W. TAYLOR \\ London
}

The presence of pigment granules in the anterior vitreous, in the absence of previous ocular surgery, is almost pathognomonic of a retinal break (Shafer, i 965). To investigate the accuracy of this observation, a consecutive series of patients with retinal holes were examined.

\section{Method}

All patients presenting to us over an 18 -month period at Moorfields Eye Hospital with rhegmatogenous retinal detachment or flat retinal holes were examined by slit-beam biomicroscopy, using the Haag-Streit slit lamp. The presence or absence of pigment granules was noted in each eye. Patients who had had previous ocular surgery were excluded.

\section{Results}

43 eyes with rhegmatogenous retinal detachment and twenty eyes with flat retinal holes were examined. Table I shows the results in the patients presenting with retinal detach8 ment. Table Il shows the results in the patients presenting with flat holes. Therefore in the 63 eyes showing retinal holes, 52 had pigment granules, giving a false negative result of 17 per cent. Of the 49 eyes showing no retinal holes, none showed pigment cells, giving a false positive result of nil.

Table I Patients with retinal detachment (43)

\begin{tabular}{|c|c|c|c|}
\hline \multicolumn{2}{|l|}{ Pigment granules } & Present & Absent \\
\hline \multicolumn{2}{|c|}{$\begin{array}{l}\text { Eyes presenting with rhegmatogenous } \\
\text { retinal detachment }\end{array}$} & 42 & I \\
\hline \multirow[t]{3}{*}{ Contralateral eye: } & No pathology & o & 34 \\
\hline & Flat holes & o & 3 \\
\hline & Lattice, no holes & o & 2 \\
\hline
\end{tabular}

Table II Patients with flat retinal holes

\begin{tabular}{|c|c|c|c|}
\hline \multicolumn{2}{|l|}{ Pigment granules } & Present & Absent \\
\hline \multicolumn{2}{|c|}{ Eye presenting with flat holes } & 9 & 6 \\
\hline \multirow[t]{3}{*}{ Contralateral eye: } & No pathology & o & I I \\
\hline & Flat holes & $\mathbf{I}$ & $\mathbf{I}$ \\
\hline & Lattice, no holes & o & 2 \\
\hline
\end{tabular}




\section{Discussion}

The presence of pigment granules in the anterior vitreous is Ioo per cent. pathognomonic of a retinal hole in eyes which have had no previous surgery. 83 per cent. of eyes with open retinal holes and no previouse surgery will show the presence of pigment granules in the anterior vitreous. The pigment granules may take various forms from small discrete cells to larger clumps (Fig. I). Most often the granules are in the anterior part of the vitreous, but at times they are more posterior.

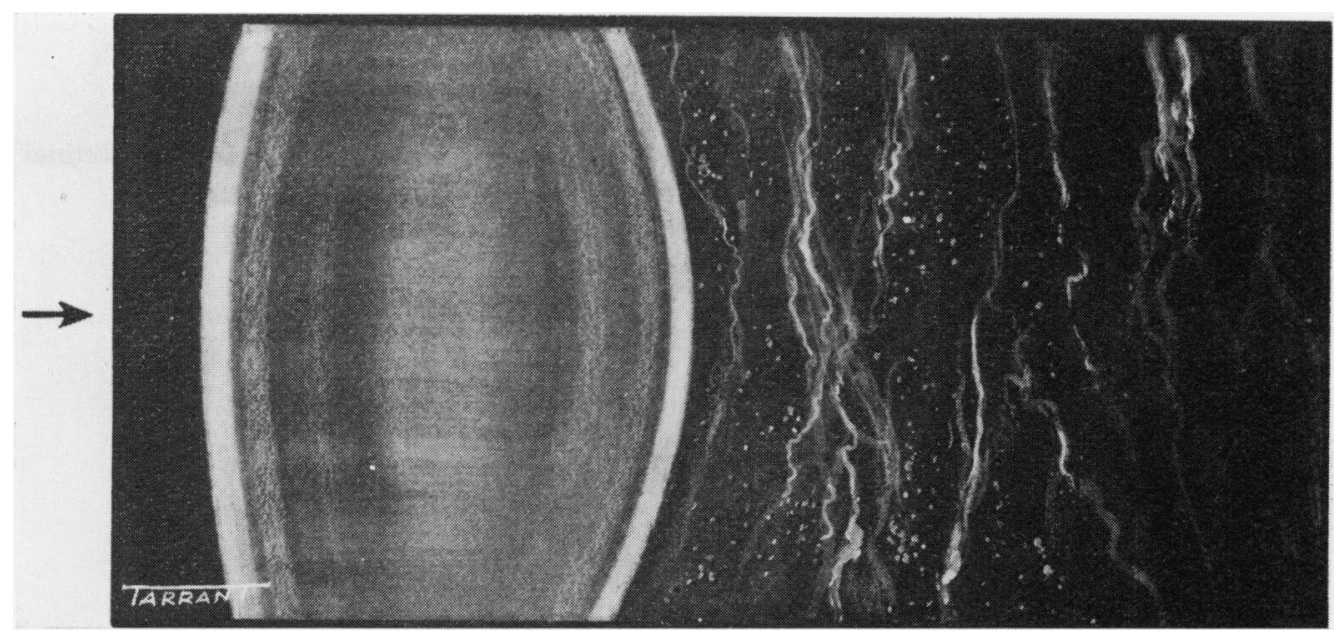

FIG. I Painting of pigment granules in vitreous

At no time was a Hruby or contact lens necessary to see the granules. In the eyes showing no granules, a contact lens examination was made of the posterior vitreous to exclude their presence. This sign is of particular value in patients who present with symptoms suggestive of a retinal tear and a flat retina. The presence of pigment granules is a sure

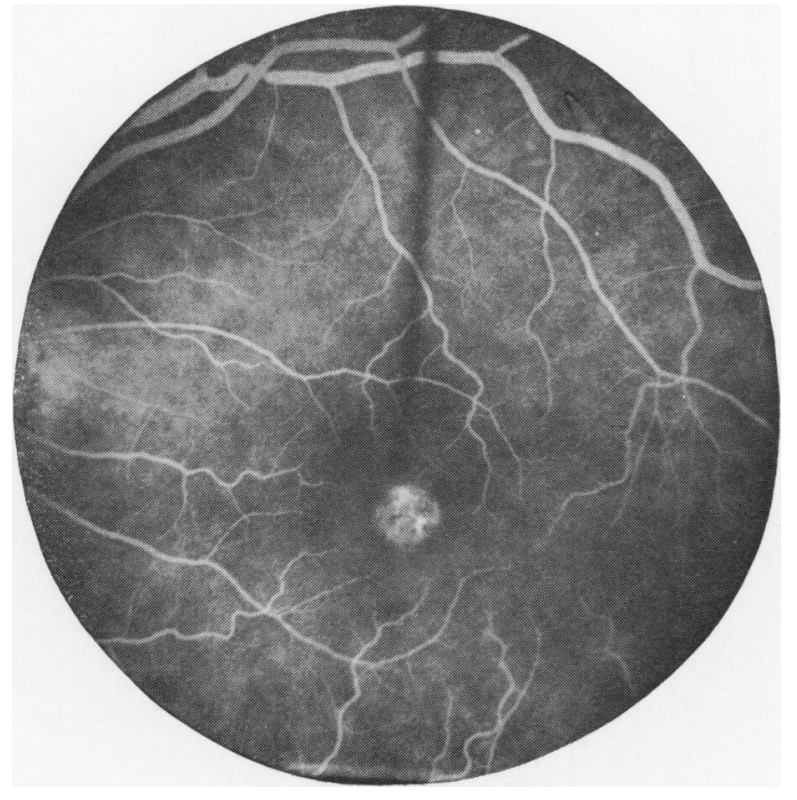

FIG. 2 Fluorescein angiography of $a$ macular hole 
indication of a retinal tear. The source of the pigment granules is not known, but we suspect that they arise from the pigment epithelium. Evidence in support of this is offered by defects of the pigment epithelium at the site of a retinal hole shown by fluorescein angiography (Fig. 2). In contrast, a pseudo-hole, as at the macula, shows no disturbance of the pigment epithelium.

We thank the Consultant Surgeons at Moorfields Eye Hospital for allowing us to examine their patients and in particular Mr. L. G. Fison; we also thank Mr. T. Tarrant for the art work.

\section{Reference}

SHAFER, D. M. (1965) In "Controversial Aspects of the Management of Retinal Detachment", ed. G. L. Schepens and C. D. J. Regan, p. 51. Churchill, London 